\title{
Cartas y otros documentos privados: el valor concedido
}

Letters and other private documents: the value granted

Judith Riquelme

jriquelme@utem.cl

Universidad Tecnológica Metropolitana

Chile

\section{Resumen}

El artículo plantea la importancia de la documentación íntima como fuentes de investigación. Analiza correspondencia inédita conservada bajo iniciativa de archivos privados y la necesidad de dar a conocer situaciones de vidas afectadas por contextos de violencia local o universal. Sostiene la relevancia del acceso, preservación y difusión, así como el rol de los Archivos. Pretende despertar el interés multidisciplinario en relación a este tipo de fuentes.

Palabras claves: correspondencia - cartas - fotografías - postales - documentos privados archivos - Holocausto - dictadura - Chile.

\begin{abstract}
The article raises about the importance of intimate documentation as sources of research. It analyzes unpublished correspondence preserved under the initiative of private archives and the need to make known situations of lives affected by contexts of local or universal violence. It maintains the relevance of access, preservation and dissemination, as well as the role of the Archives. It seeks to arouse the multidisciplinary interest in relation to this type of sources.
\end{abstract}


Keywords: correspondence - letters - photographs - postcards - private documents archives - Holocaust - dictatorship - Chile.

Emprender la búsqueda y realizar estudios de fondos documentales privados puede ser considerado marginal dentro del variado universo custodiado por los Archivos. Más aun hoy, que el mundo de la información aparenta no tener límites. Las proyecciones de Cisco Systems, relacionadas al estudio de tráfico global de internet ${ }^{1}$ estima que en 2016 se sobrepasara el zettabyte ${ }^{2}$ y duplicara en el 2019.

Si bien la Sociedad de la Información no se limita a internet y su finalidad es la difusión, el acceso al conocimiento, no sería posible pensar en tales flujos de datos sin el desarrollo explosivo que han tenido las Tecnologías de la Información (TI) las cuales se constituyen en el soporte de los sistemas de información que prestan servicios a los ciudadanos que desean profundizar sobre determinados temas. En ese contexto las instituciones como que custodian información como los Archivos, bibliotecas, se ven enfrentado a grandes desafíos respecto al acopio de información documental. ¿Qué resguardar, para que y por qué? Para Derrida (1994): "reconstruir toda una historia por medio de la compilación de un centenar de documentos es imposible".

Norbert Wiener en 1948, instala a la información en un espacio sobresaliente de las esferas económicas, sociales, políticas. En nuestros días esto es así. Hoy la ubicuidad de la información es indiscutible, es decir el acceso, captura, almacenamiento y distribución está disponible desde prácticamente desde cualquier dispositivo móviles (teléfonos inteligentes, laptops, Tablet, entre otros) y desde cualquier punto del planeta. Junto a las apps (aplicaciones móviles) a través de internet, han permitido un tipo de comunicación instantánea, y efímera.

1 The visual networking index. http://www.cisco.com/c/en/us/solutions/collateral/serviceprovider/visual-networking-index-vni/complete-white-paper-c11-481360.html 2 Zettabyte, equivale mil millones de terabytes o un billón de gigabytes. 
Las personas desean tener acceso en tiempo real a información significativa desde cualquier lugar del mundo. Esto situación presenta constantes desafíos y oportunidades para las Unidades de información.

Actualmente la mayoría de los jóvenes (nacidos desde 1980 en adelante) son nativos digitales, lo que los hace reconocer de modo natural las herramientas de la web. (blogs, wikis, redes sociales). El uso permanente del mundo virtual facilita las relaciones de los ciudadanos, y propicia la difusión del patrimonio documental de las instituciones que pueden darse a conocer, generar actividades culturales y redes de apoyo más allá de los limites tradicionales.

No obstante, parece ser que, en el mundo de virtual no existen más las cartas, ni las fotografías, ni los recuerdos personales como una flor seca entre las hojas de un libro. En los tiempos que corren, no hay tiempo para recordar. Y conservar o compilar "papeles" puede ser un acto de memoria para unos pocos, un acto casi por desaparecer, por extinguirse.

Cartas, postales, diarios de viajes se convierten en manos del investigador en compendios literarios, o la clave del destino heredado o en una oportunidad de quebrar la desigualdad en un esfuerzo por ordenamiento sociocultural que aspira al acceso del conocimiento de todos los miembros de la sociedad.

El estudio del individuo, requiere que el investigador tenga una mirada crítica y profunda, ampliada con un acceso permanente a nuevas fuentes documentales. Lo cual conlleva necesariamente a ocuparse en estudio de documentación de distinto origen. 
Los documentos autobiográficos recogen aspectos histórico-biográficos que resultan interesantes para reconstruir historias personales de poco conocimiento público y muy probablemente escasamente investigadas. (Autobiografías, diarios íntimos, cartas, hojas, testamentos, partidas de nacimientos de casamientos y defunciones, postales, narraciones, dibujos).

\section{Cartas: el valor conferido.}

Además del valor objetivo que pueden tener los documentos de archivo está el valor conferido. Estos registros contienen imágenes, textos y dibujos que pueden verse y entenderse. Se constituyen como "espacios" de almacenamiento de experiencias vividas.

Las cartas, manuscritas en frágiles papeles, y las fotografías antiguas instantáneamente nos sitúan en el pasado. Las tecnologías de la información convierten en segundos el ayer en hoy. Los documentos como las cartas pasan a ser obsoletos, desechos, remplazables por copias digitales en alta calidad.

Las cartas, son la forma de lenguaje escogida para expresar en modo extendido y de la manera más íntima posible, ideas sentimientos, intenciones, deseos primordiales de confesar a otro. Lenguaje sin adornos gestuales. Simplemente la soledad de las palabras cargadas de energía.

Los investigadores miran al futuro aun cuando estén "leyendo" el pasado. El pasado que guarda la memoria de hechos que pueden repetirse, si no se mantienen en el presente. 
Los documentos de los Archivos, son testigos de lo que puede ser sobrevivir, de las heridas, de lo no dicho. Fragmentos de vidas muchas veces casualmente guardados. Son ante todo pruebas de lo que se resiste a desaparecer a desvanecerse.

En 1941 comenzaron los preparativos para construir Auschwitz, a cargo de Hans Stosberg. Los especialistas que examinaron el terreno, documentaron ampliamente con fotografías. En varias decenas de estas fotografías es posible encontrar similitudes con postales de la época. Jacek Malczynski (2016) estableció que los originales de las fotografías fueron utilizados en la creación de postales que hoy se encuentran en Yad Vashem. Las postales, todas provenientes de Polonia contienen saludos, expresiones de amor, nostalgia por los seres queridos que no están cerca.

La correspondencia era el medio para enviar noticias esperando que llegaran a su destino, si nada fallaba. En muchas ocasiones guardaban noticias no gratas.

Documentos oficiales con reglamentos de los Campos de Concentración son conservados en la intimidad de las familias que perdieron a alguno de sus miembros, una forma de no olvido:

“Campo de Concentración". Weimar Buchenwald El día de la liberación aún no puede ser informado. Las visitas en el campo están prohibidas. Consultas no tienen sentido.

Resumen del Reglamento del campo:

\footnotetext{
${ }^{3}$ Documento original en alemán, traducción de Lore Hepner. Colección Familia Drexler. Archivo Histórico de Judaísmo Chileno
} 
Cada interno puede recibir dos cartas o dos tarjetas postales al mes y a su vez también enviar. Las líneas en las cartas deben ser claras y fáciles de leer.

Envíos que no cumplen con estas exigencias no serán despachados o entregados. Paquetes, cualquiera que sea su contenido, no pueden ser recibidos.

Envíos de dinero son permitidos; dentro del campo se puede comprar de todo.

Se permite recibir diarios nacionalsocialistas, pero el interno mismo debe abonarlos en la oficina de correos del campo de concentración.

El Comandante del Campo

La nostalgia es tema obligado en las cartas de los primeros migrantes que llegaron al sur de Chile, dan algunas noticias de la vida en la nueva patria, en otro continente, veamos parte de la carta enviada por Abraham Goldenberg ${ }^{4}$ a sus parientes en Alemania:

Querida Hermana y Cuñado,

"Somos muy lentos para escribir, pero Uds. no lo son menos...Si escribimos poco, es porque de aquí no sabemos mucho qué escribir, fuera de que estamos, como también hoy, gracias a Dios, todos bien y tranquilos. ... Ahora les ruego una vez más que contesten luego, para que sepamos que la carta les ha llegado."

\footnotetext{
${ }^{4}$ Colección Manuscritos. Archivo Histórico de Judaísmo Chileno. Carta fechada en Chillan en 1888 
La correspondencia en aquel tiempo se superponía a la respuesta esperada. Y parecía ser que las mujeres eran más dadas a escribir y mantener vivo el contacto a pesar de la distancia.

"Ayer tuve carta de mamá y ya que escribe que tú estás angustiada porque hace tanto tiempo que no has sabido de nosotros, decidí de inmediato escribirte, lo que hacía tiempo había sido mi intención. Abraham también me prometió ayer que ellos escribirán luego, pero tú sabes, querida Minna, lo difícil que es que los hombres se decidan a hacerlo.

Ojalá todos Uds. estén bien. El niño más pequeño de Uds. ya debe ser todo un hombre, pero todavía no me has escrito como se llama el niño.

Nosotros también tenemos nuevamente un bebé, una niñita, que nació el 25 de agosto. A través de mamá habrás recibido los retratos de nuestros hijos, los que no salieron muy bien.

Nosotros estamos bien, muchos saludos de Max y Otto agregando también para tu marido, quedo tuya"

Mathilde Goldenberg ${ }^{5}$

Estas cartas celosamente guardadas por generaciones, seguramente fueron leídas y releídas una y otra vez. Mostrada a los hijos hasta que ya nadie se identificó con ellas y algunas fueron entregadas para un mejor destino a un Archivo. Otras simplemente fueron descartadas.

${ }^{5}$ Fechada en Chillán, el 20. De Sept. 1888. 
Estas cartas fueron donadas al Archivo Histórico del Judaísmo Chileno acompañadas por un álbum de fotografías de la Familia Goldenberg, que a primera vista evoca una época, en una pausa se observan los detalles de las vestimentas presencia del pasado prospero en Europa. Las fotografías reflejan lo que quieren decir sus protagonistas. Este tipo de documentos no era espontaneo o casual como lo son hoy. Especialmente con la proliferación de autofotos desde teléfonos móviles. Tampoco pretendía ser efímero sino perpetuar la memoria, evitar el olvido. La fotografía en el siglo XIX era privilegio de unos pocos, y en Chile incluso hasta los años 70 en las zonas rurales era un documento que el campesino solo poseía al obtener la cedula de identidad. Esta situación es observable en los archivos de detenidos desaparecidos de FUNVISOL ${ }^{6}$ o en el Mural de fotografías del Museo de la Memoria.

La necesidad del ser humano en situación de peligro le lleva a querer dejar testimonio de sus deseos o sentimientos para sus familiares. Nos parece relevante destacar el caso de Litre Quiroga quien, el 11 de septiembre 1973 desde La Moneda, escribió a sus hijos, su esposa y su madre:

\section{7 “Niñitos:}

Pórtense bien y cómanse toda la comida. Estudien mucho y ayuden a su mamá.

El papá seguramente no podrá verlos quizá hasta cuándo.

No vean tanta televisión y pórtense como corresponde a niños buenos. ...no se olviden de su papito..."

En la breve carta a su esposa se lee:

\footnotetext{
${ }^{6}$ Fundación de Documentación y Archivos de la Vicaria de la Solidaridad.

${ }^{7}$ Las cartas de Litre Quiroga se pueden consultar en la biblioteca digital del Museo de la Memoria y los Derechos Humanos. http://www.bibliotecamuseodelamemoria.cl/
} 
"Silvia: Son las 12.30. Ya bombardearon la Moneda...yo espero en mi oficina con la dignidad del caso...no sé qué será de mi...si no nos vemos más recuerda a tu marido que siempre te quiso”

Un angosto trozo de papel, de marcados pliegues guarda un íntimo y valiente mensaje de despedida a su Madre:

"Mamy:

Son las 5:30 de la tarde estamos esperando que nos vengan a buscar...no te preocupes por mi...”

Litre tenía 33 años, su cuerpo fue encontrado junto al de Víctor Jara el 16 de septiembre de 1973.

Los documentos privados reflejan momentos cotidianos o sucesos difíciles, como las guerras, o el exilio eran esperados por meses. Muchas veces era lo único que nos quedaba de un ser querido.

${ }^{،}{ }^{H}$ Han pasado años desde que hemos sabido por última vez una de la otra. Espero y te deseo, que mientras tanto hayas logrado forjarte una buena posición y te sientes contenta en tu nueva patria. Nosotros estamos todos bien. Sin embargo, la guerra también nos ha maltratado muchísimo y es un verdadero milagro que los cuatro estemos con vida. En septiembre del 44 fuimos internados por la GESTAPO. Papá en Buchenwald, mi marido en Dachau y yo en Ravensbrueck. Habrás oído hablar de esos famosos campos

\footnotetext{
${ }^{8}$ Skolovic Trude. Ljubljana, Yugoslavia 25.XI.1946. Traducción Lore Hepner. Colección Familia Drexler. Archivo histórico de judaísmo chileno.
} 
y es por eso que te ahorro un detallado informe de los horrores y las miserias que hemos soportado allá. Para que solamente tengas una vaga idea menciono que, al terminar la guerra mi peso era de $34 \mathrm{Kg}$. y el de Papá $32 \mathrm{Kg} \ldots$,

Estas cartas eran la única forma de intentar tener noticias de la familia o amigos. Ocupando todos los espacios de la hoja de papel y dejando las peores noticias para el final. Continua:

“... ¿Que fue de Hanny? Tampoco sabemos algo del destino de la tía Rosa. ¿Dónde se encuentra Hansi y tía Rosa? ¿Cómo está la familia Hochaeusler? ¿Has sabido algo del tío Jacque, Richard, Familia Weiss?

Probablemente sabes, que el tío Leo y la tía Frieda murieron durante su internación. Los pobres. En noviembre 41 - 1942 se les internó en Theresienstadt, luego se les transportó a Riga. En Riga trabajaron ambos en un aeropuerto. Alojaron por algún tiempo en el Ghetto. Más adelante en una Cervecería vacía. Allí soportaron hasta comienzos de 1943. Luego murieron ambos."

En ocasiones la carta es escrita y solo tiene la misión de ser el testimonio privado y fragmentado de una vida ${ }^{9}$ que relata los horrores de Auschwitz

“...La retira la hicimos a pie en pleno invierno sin comida ni bebida. Los que no podian seguir a los SS, los guardias fusilaron a una de mis hermanas... fui víctima de esta crueldad. La mitad del grupo ha muerto de hambre, enfermedades..."

\footnotetext{
${ }^{9}$ Testimonio de Ana Sugar. Memoria Viva, p.273.
} 
O el último recuerdo de una abuelita que es atesorado por su nieta que hoy es una anciana. ${ }^{10}$ "Mi querida y dulce, con mucho gusto cumplo el deseo de escribir unos versos para ti, porque no sé si alguna vez en la vida...podré volver a escribirte o verte. A pesar que no hay nada que anhele más...He envejecido mucho, he pasado por tanto que físicamente no me reconocerías, estoy desfigurada, enflaquecí enormemente...Nos erradicaron de nuestra patria, nadie sabe para dónde dicen que a un asilo donde uno va a estar con unos diez o veinte desconocidos en una pieza ..."

En muchas ocasiones son pruebas a los ruegos desesperados de una madre, como vemos más abajo la respuesta de la Embajada Británica a la señora Simonshon ${ }^{11}$.

"Entiendo que Ud., conoce la simpatía de todos nosotros en la Embajada en lo que se refiere a la situación difícil en la cual Ud., se encuentra junta[o] con las otras madres de origen judio, por causa de la decisión del Gobierno Chileno para no admitir la llegada de sus hijos que residen ahora en Inglaterra, Sin tomar en cuenta el hecho de la residencia permanente de Ud. En Chile..."

El mandato parece conminar a no destruir cartas, ni fotografías gastadas que despiertan pensamientos y memorias diversas, a veces desconocidas.

\footnotetext{
${ }^{10}$ Testimonio de Ana María Wahrenberg. Memoria Viva. P.163

${ }^{11}$ Documento disponible en el Archivo Histórico del Judaísmo Chileno.
} 
Los documentos personales que fueron parte de una vida (escribir, enviar, recibir, leer y coleccionar) resultan esenciales, entendemos que sin ellos no podríamos afrontar ni valorar los procesos de creación y revolución de la humanidad desde todas las voces.

Cyrulnik (2011) señala que la "historizacion" es una forma de ayudar a los agredidos, escribir sus historias de vida hace menos aplastante la mirada del otro frente a la degradación. Los detenidos de los Campos de Concentración durante la Segunda Guerra podían comunicarse con el mundo exterior a través de la Cruz Roja Internacional, que con dificultad entregaba mensajes de un máximo de 25 palabras previamente censurados. (Hepner, 1990)

El trabajo a partir de fuentes muchas veces inéditas o escasamente investigadas es un llamado de atención para los profesionales de la información. En muchas ocasiones quienes están a cargo de los Archivos se ven enfrentados a cuestionamientos sobre el valor de conservar o no este tipo de documentos. La respuesta puede estar en la importancia de construir una explicación del pasado desde todas las voces, especialmente de los individuos marginales.

Los documentos personales son una forma de transmitir la voz de personas comunes, una construcción de experiencias alternativas a la historia tradicional.

En la mayoría de los casos la documentación se conserva en a través de variados y contradictorios escenarios que no dejan siempre claro la forma de adquisición de un el documento.

De todos modos, hay aspectos que no hay que perder de vista, la conexión entre lo público y lo privado. Muchas veces encontramos en los documentos personales relatos de vidas afectadas por hechos de la Historia Universal, considerados sin valor, pero de indudable importancia patrimonial. 
Los documentos íntimos han transcurrido muchas veces en espacios de silencios obligados y de abnegación desmedida. Habitualmente se considera que la construcción de las memorias son un testimonio de personas excepcionales, protagonistas de acontecimientos históricos importantes. Un ejemplo de ello es lo vivido durante la Segunda Guerra Mundial, la huella indeleble que quedo en la memoria de niñas judías de entonces, se puede "borrar" si los relatos de vida y los documentos probatorios de las atrocidades vividas no están al acceso de las nuevas generaciones, si los investigadores no se ocupan de su estudio y los archivos no cumplen con tu labor de acopio, preservación y difusión. Debemos asegurar una transmisión adecuada de recuerdos y vivencias de una generación a otra, no para transferir el dolor a veces instintivamente ocultado y escondido. Si no para fortalecer la igual y transmisión de valores de respeto e igualdad.

Recuperar recuerdos, hechos, imágenes, a través de los documentos privados posibilita el compartir las vivencias y facilita el dialogo intergeneracional y la sensación en los testigos aun presentes la permanencia de su historia y la de otros en el tiempo.

Bertaux (1989) señala que construir la historia de una vida, es una práctica de varios siglos. Esboza tres modalidades distintas de hacer la historia de una vida: la biografía, la autobiografía y el relato de vida.

Muchas de estas personas se atrevieron a comunicar sus experiencias mediante las autobiografías, y las cartas, u otros tipos de documentos que atesoraron y coleccionaron apasionadamente en su vida.

Desde el punto de vista archivístico los documentos privados son de gran valor. Testimonio de gente común que vivieron momentos cruciales de la historia de la humanidad. El archivero debe reconocer en los documentos de colecciones privadas un medio para nuevas investigaciones. Las cartas, consideradas relatos de segundo orden, eran una herramienta de 
comunicación habitual hasta mediados del siglo pasado, muchas no han sido conservadas y otras que han permanecido resguardadas sin saber porque y para qué. Se corre el riesgo de que desaparezcan por ser consideradas relatos de asuntos privados e individuales sin importancia para la memoria colectiva. Según Huyseen (2015), recordar solo tiene sentido cuando el recuerdo se usa para crear o imaginar un nuevo futuro.

\section{A modo de conclusión}

El objetivo de un Archivo no es guardar por guardar lo que busca es poder comunicarse con un otro y en eso las tecnologías han ayudado, pero con la masificación de información no ha logrado ciertas facultades de comunicación tradicionales como son las cartas. La sensación de tocar oler, sentir una bi-dimensionalidad del objeto, hace que ese objeto sea un algo real y emocionalmente tangible que logra un nivel de comunicación intimo con el otro.

Los fragmentos de cartas citados en este artículo no han perdido su fuerza original y pueden ser fuente de reflexión permanente.

En algún minuto la tecnología va a alcanzar esta bi-dimensionalidad, pero nuevamente va a necesitar el original. Los códigos emocionales contenidos en los documentos son percibidos, entendiendo la precepción como ver sentir e interpretar mentalmente.

Hay un espacio que es más importante que los archivos en sí, su valor está en las emociones que se han logrado custodiar en ellos y su posterior trasmisión. Es en este sentido que la carta cobra un lugar especial.

Los documentos de Archivo, muchas veces son una advertencia del lado oscuro de la condición humana, pero también son reflejos de sus aspectos virtuosos, la resiliencia y la capacidad de volver a comenzar. 
Los documentos personales contribuyen a llenar el vacío existente sobre el conocimiento de los grupos marginados cuyos relatos muchas veces considerados de segundo orden. Los documentos personales que conforman los fondos privados pueden contribuir a dar voz a las minorías en la medida que su recuerdo no es empequeñecido a los ojos de investigador.

El conocimiento y la experiencia en el uso de las tecnologías está creando nuevas oportunidades de preservación y acceso. Los Archivos deben generar estrategias que permitan adquirir, y transmitir la información que custodian con el menor costo posible y con calidad.

\section{Fuentes}

Correspondencia familiar (1940-1944). Colección Drexler. Archivo Histórico de Judaísmo Chileno.

Correspondencia HICEM (1942). Colección Digital CREJ. Archivo Histórico de Judaísmo Chileno.

Sub Fondo Günter Bohm. Serie manuscritos. Familia Goldenberg (1888). Archivo Histórico de Judaísmo Chileno.

\section{Referencias}

Bertaux (1989): Les récits de vie comme forme d'expression, comme approche et comme mouvement. En Pineau et Jobert (coord.): Histoires de Vie. Tome I. Paris. L'Harmattan, 17-38.

Cartas de Litre Quiroga. Biblioteca digital del Museo de la Memoria y los Derechos Humanos. http://www.bibliotecamuseodelamemoria.cl/ consultada en agosto de 2016

Cyrulnik, B. (2011). Morirse de vergüenza: el miedo a la mirada del otro. Buenos Aires: Debate.

Hepner, L. (1990) Respuesta a Albert...una crónica familiar. Santiago: Caligrafía azul. 
Malczynski, J. (2016). Saludos desde Auschwitz. Postales desde la ciudad del exterminio. Wyborcza.

Memoria Viva: Historias de refugiados y sobrevivientes de la Shoá que se albergaron en Chile. Un homenaje a Chile por haberlos acogido. (2016) Santiago: Ograma impresores. $659 \mathrm{p}$.

Szendy, P. (2015). En lo profundo de un oído: una estética de la escucha. Santiago: Salesianos. 126p.

The visual networking index. Consultado en noviembre 2015 http://www.cisco.com/c/en/us/solutions/collateral/service-provider/visual-networkingindex-vni/complete-white-paper-c11-481360.html 